\title{
Endoscopic Surgery of Skull Base Chordomas
}

\author{
Neil C-W Tan ${ }^{1}$ Yuresh Naidoo ${ }^{1}$ Sakiko Oue ${ }^{1}$ Hamish Alexander $^{2}$ Simon Robinson ${ }^{2}$ \\ Agadha Wickremesekera $^{2}$ Steve Floreani ${ }^{1}$ Nick Vrodos $^{3}$ Steve Santoreneos ${ }^{4}$ Eng Ooi ${ }^{5}$ \\ Matthew Mcdonald ${ }^{3}$ Peter-John Wormald ${ }^{1}$
}

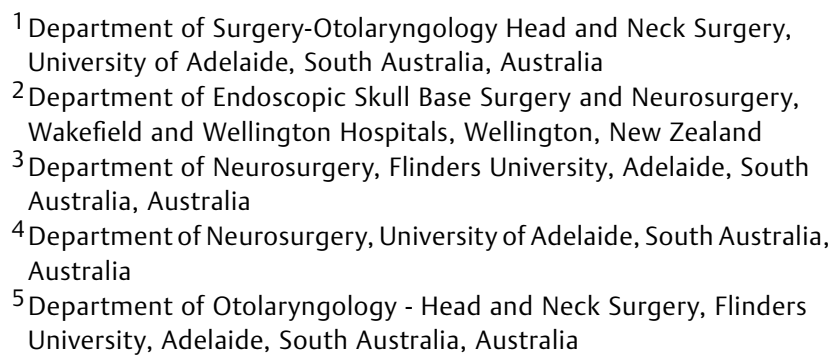

\begin{abstract}
Address for correspondence and reprint requests Prof. P-J. Wormald, M.D., F.R.A.C.S., F.R.C.S., Department of Surgery-Otolaryngology Head and Neck Surgery, Adelaide and Flinders Universities, The Queen Elizabeth Hospital, 28 Woodville Road, Woodville, South Australia, Australia, 5011 (e-mail: peterj.wormald@adelaide.edu.au).
\end{abstract}

J Neurol Surg B 2012;73:379-386.

\section{Introduction}

The endoscopic transnasal approach to the mid- and posterior skull base is an increasingly popular route of access in the treatment of midline skull base lesions such as clival chordomas. Chordomas are rare neoplasms with an incidence of
0.08/100 000. ${ }^{1}$ They arise from remnant notochord cells found predominantly within the clivus (30 to 40\%) and sacrococcygeal regions (40 to $50 \%$ ) but can be found anywhere along the spinal column. ${ }^{2}$ Clival chordomas tend to present late with associated neurological impairment due to involvement of the lower cranial nerves. ${ }^{3}$ Median survival is received

January 6, 2012

accepted

March 28, 2012

published online

August 29, 2012
Copyright (C) 2012 Georg Thieme

Verlag KG Stuttgart · New York
DOI http://dx.doi.org/ 10.1055/s-0032-1321508. ISSN 2193-6331. 
poor (6.3 years) with a 5-year survival rate of 36 to $68 \% .^{1,4}$ Metastases occur in $\sim 30 \%$ with a predilection for lung, bone, skin, lymph nodes, and liver. ${ }^{5-7}$

Access to the clivus has historically been through anterior craniotomies, but the endoscopic transnasal approach is increasingly being utilized. Initial reports have shown that this is equivalent to the traditional open approach in terms of residual disease, recurrence, surgical and functional morbidity, and mortality. ${ }^{8-15}$

This study aims to evaluate the management of skull base chordomas surgically resected via an endoscopic transnasal approach by the South Australian Endoscopic Skull Base Unit (SAES) and Wellington Skull Base Unit since 2002. The safety and efficacy of the procedure, role of the multidisciplinary team approach, and areas for further technical refinement are analyzed.

\section{Materials and Methods}

\section{Study Design and Population}

We present a retrospective case series of 14 consecutive patients who underwent endoscopic transnasal resection of clival chordomas between 2002 and 2011. Ethical approval was obtained from the Institutional Review Board, and tumors approached solely by alternative surgical methods were excluded from the study. Demographic and clinical information were compiled by reviewing patient charts and operation notes. Tumor size was calculated by measuring the anteroposterior, craniocaudal, and horizontal diameters on preoperative magnetic resonance imaging (MRI) scans, and tumors were graded according to the Snyderman ${ }^{16}$ surgical level, which describes whether a tumor has a cortical cuff, vascular attachment, or vascular encasement. Tumor grades are presented in - Table 2. The extent of resection was obtained from the operative report and correlated with review of intraoperative videos, postoperative histopathology, and radiology reports. The literature was then reviewed to compare our results with those from other published series.

\section{Surgical Method}

An endoscopic transnasal approach with Image Guidance (StealthStation ${ }^{\circledR}$, Medtronic, Minneapolis, MN, USA) was used with MRI and computer tomography (CT) sequences obtained immediately prior to surgery in all cases.

The nose is prepared with $2 \mathrm{~mL}$ of $10 \%$ cocaine, $2 \mathrm{~mL}$ of 1:1000 adrenaline, and $2 \mathrm{~mL}$ of saline applied topically with neurosurgical patties. The septum and lateral nasal wall are injected with $2 \mathrm{~mL}$ of $2 \%$ lignocaine and 1:80,000 adrenaline. The patient is placed in reverse Trendelenburg position at an approximate angulation of 30 degrees. The anterolateral thigh or abdomen is prepared for harvesting of fat and fascia to repair the dural defect. An indwelling catheter, invasive blood pressure monitoring, prophylactic antibiotics, and deep vein thrombosis (DVT) prophylaxis are used.

The first step consists of raising a nasoseptal flap as described by Haddad ${ }^{17}$ to be used later for the skull base reconstruction. The septal flap is then transferred from the nasopharynx and placed into the maxillary sinus through a wide middle meatal antrostomy, where it remains for the remainder of the resection. Where possible, the flap is raised contralateral to the tumor when there is significant lateral extension that will require a transpterygoid extension of the dissection. Endoscopic sinus surgery is then performed with the aim being to (1) provide access for a two-surgeon, fourhanded operation; (2) identify key landmarks such as the skull base, orbit, orbital apex, carotico-optic recess, optic nerve, and internal carotid artery; and (3) expose the skull base overlying the area to be resected.

The approach is dependent upon the location of each tumor, but in general a wide removal of the clivus is needed. The entire floor of the sphenoid between the vidian nerves is resected. The inferior extent depends upon the position of the tumor but can extend as far as the second vertebral arch. The paraclival carotid artery on each side is skeletonized and identified, and the floor of the pituitary fossa is removed (for higher tumors). The bone of the clivus is resected with wide exposure of the underlying dura. Tumor is often encountered prior to the dura and is removed before the dura is opened. The tumor is then resected using well-established neurosurgical techniques using a combination of sharp and blunt dissection. The tumor is mobilized from the surrounding neurovasculature and removed. Hemostasis is achieved with bipolar cautery and/or the use of Gelfoam paste (Pharmacia and Upjohn Company, Kalamazoo, MI, USA) and warm saline irrigation. Once hemostasis has been confirmed, the skull base defect is reconstructed using the septal flap as the workhorse. Our technique uses an intradural fat layer, followed by an underlay of tensor fascia lata (or rectus abdominus), and overlay of fascia with the nasoseptal flap as the final layer. The nasoseptal flap is positioned without tension and care is taken to make sure that it is in contact with bone at the periphery of the defect to promote revascularization. The repair is then supported with ribbon gauze soaked in bismuth iodoform paraffin paste (BIPP).

\section{Follow-up}

Follow-up was at 3 months postoperation with clinical assessment and MRI scanning. Patients with evidence of nasal crusting or discharge had microbiological swabs taken. If these were positive for bacteria, culture-sensitivity-guided antibiotics were prescribed. All patients received saline nasal douching. MRI scans were repeated yearly thereafter unless clinically indicated otherwise.

\section{Results}

Fourteen patients (eight male and six female) underwent endoscopic resection of clival chordomas with a median age of 48.5 years (interquartile range [IQR] 41.9 to 54.5 ). Clinical data are summarized in -Tables 1 and 2. Seven patients underwent primary endoscopic endonasal resection with the other seven undergoing revision surgery. All revision cases had their primary surgery in another institution; two had undergone external resection by craniotomy, two had transoral excision, two underwent a previous combined transnasal 


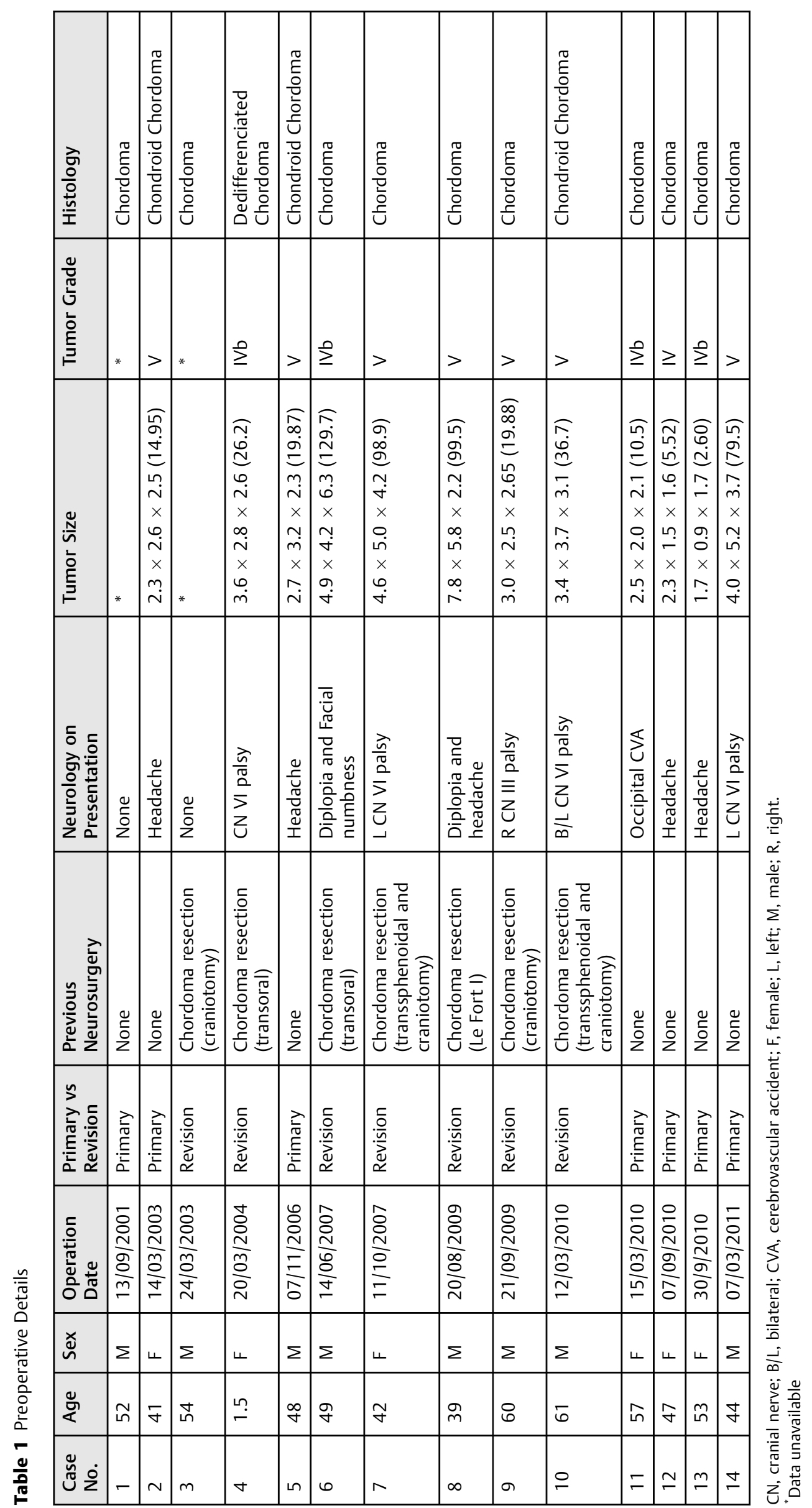



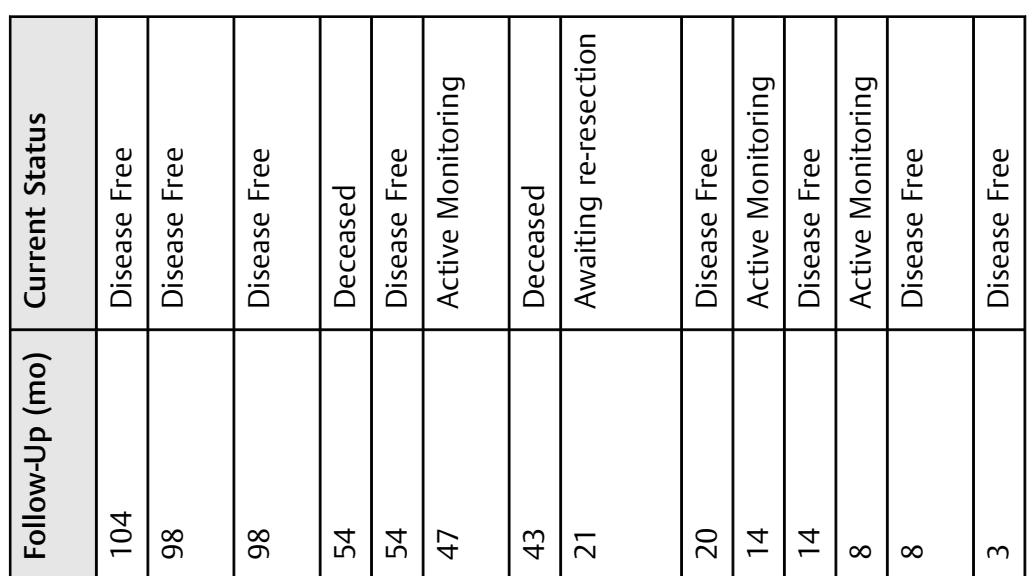

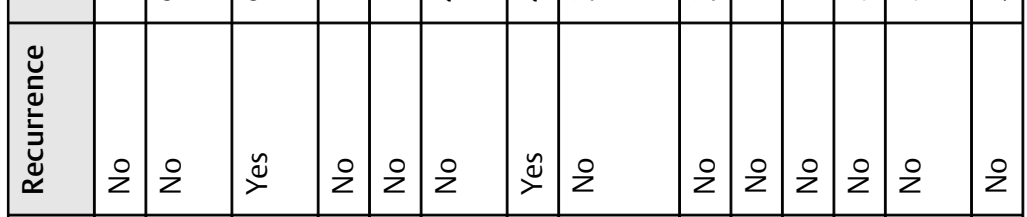

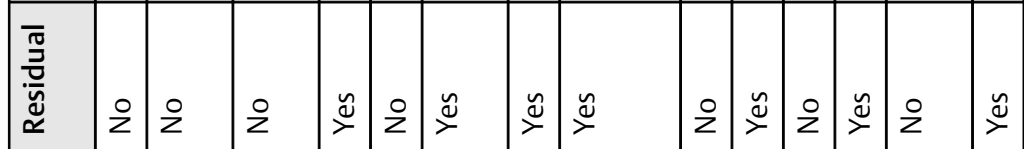

\begin{tabular}{|c|c|c|c|c|c|c|c|c|c|c|c|c|c|c|}
\hline 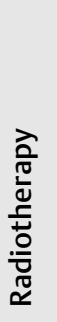 & 20 & io & 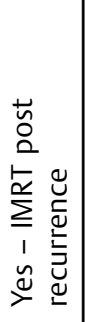 & 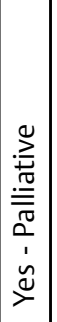 & $\stackrel{0}{z}$ & 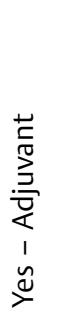 & 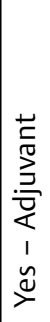 & 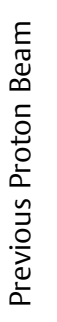 & 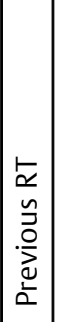 & 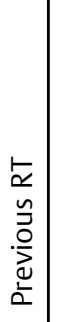 & z & z & 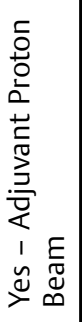 & z \\
\hline نِ & 6 & $\infty$ & $\nabla$ & $\bar{m}$ & $\bar{m}$ & $\stackrel{\eta}{\sim}$ & $\stackrel{\simeq}{\simeq}$ & $\approx$ & $\simeq$ & $\nabla$ & $\nabla$ & $\mp$ & 0 & $\bar{\sim}$ \\
\hline
\end{tabular}

\begin{tabular}{|c|c|c|c|c|c|c|c|c|c|c|c|c|c|c|}
\hline 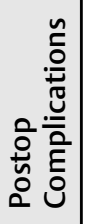 & & $\begin{array}{l}\text { 苛 } \\
\text { 嵌 }\end{array}$ & $\overline{\bar{E}}$ & $\overline{\bar{z}}$ & 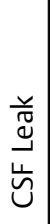 & 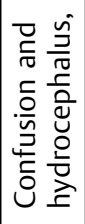 & $\overline{\bar{z}}$ & 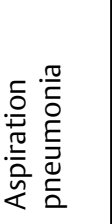 & 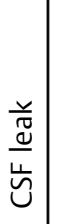 & $\overline{\bar{z}}$ & $\overline{\bar{z}}$ & $\overline{\bar{z}}$ & $\overline{\bar{z}}$ & 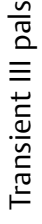 \\
\hline 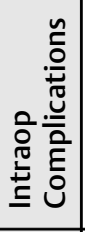 & $\overline{\bar{z}}$ & 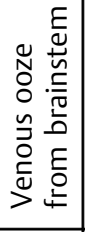 & $\overline{\bar{z}}$ & $\overline{\bar{z}}$ & $\overline{\bar{z}}$ & $\overline{\bar{z}}$ & $\overline{\bar{z}}$ & 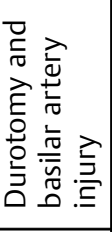 & $\overline{\bar{z}}$ & $\overline{\bar{z}}$ & $\overline{\bar{z}}$ & $\overline{\bar{z}}$ & $\overline{\bar{z}}$ & $\overline{\bar{z}}$ \\
\hline 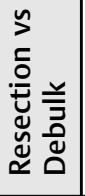 & 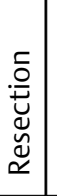 & 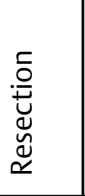 & 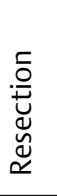 & 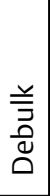 & 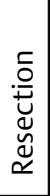 & 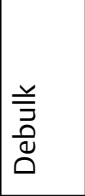 & 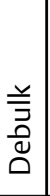 & 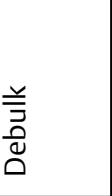 & 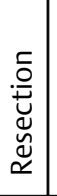 & 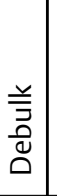 & 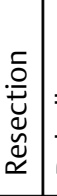 & 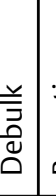 & 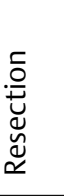 & 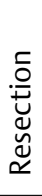 \\
\hline $\begin{array}{l}\stackrel{g}{\Xi} \\
\stackrel{\Xi}{E} \\
\text { 。 }\end{array}$ & * & $\stackrel{m}{\sim}$ & * & $\stackrel{\sim}{\sim}$ & 峜 & $\stackrel{\substack{\infty \\
\sim}}{\stackrel{\infty}{*}}$ & * & $\begin{array}{l}8 \\
0 \\
0\end{array}$ & $\bar{m}$ & $\stackrel{\infty}{\text { in }}$ & ฉి & $\bar{m} \mid$ & ষి & 怘 \\
\hline$\stackrel{\tilde{u}}{\tilde{v}} \dot{0}$ & -1 & $N$ & $m$ & $\sigma$ & in & 6 & $\wedge$ & $\infty$ & $\sigma$ & $\stackrel{ㅇ}{-}$ & $\mp$ & $\simeq$ & $\stackrel{m}{-}$ & $\stackrel{\nabla}{\square}$ \\
\hline
\end{tabular}


and external resection, and one had a Le Fort I approach. The results of the two cohorts are summarized in -Table 3.

\section{Presentation}

Only two of the seven primary cases presented with focal neurological symptoms, although a further four complained of persisting headache. Almost all revision cases noted neurological impairment, with diplopia being the most common symptom.

\section{Extent of Resection and Histology}

Complete macroscopic resection was achieved in $71 \%$ of primary as opposed to $29 \%$ of revision cases, with surgery being limited by involvement and invasion of critical structures. The remaining cases underwent subtotal resection. Overall tumor histology was reported as 10 classical chordomas, three chondroid chordomas, and one dedifferentiated chordoma.

\section{Complications}

Complications are summarized in - Table 2. One major intraoperative complication occurred in a patient undergoing revision surgery after proton beam irradiation; the patient sustained a basilar artery injury. This was repaired endoscopically with a muscle graft. Subsequent on-table angiography demonstrated good flow within the repaired vessel, and the patient did not demonstrate any neurological deficit postprocedure and to date has not has any pseudoaneurysm formation.

Postoperative complications occurred after one primary surgery and three revision cases. One patient developed aspiration pneumonia secondary to two failed extubation attempts. There was one case of postoperative confusion and hydrocephalus that settled with medical treatment. The third patient experienced postoperative emesis, which was thought to have dislodged the cranial base reconstruction causing pneumocephalus. The pneumocephalus was treated conservatively with complete resolution and no additional morbidity.

There were three postoperative CSF leaks that required endoscopic repair; two following primary (29\%) and one following revision surgery (14\%). A further two cases resolved following insertion of lumbar drain. All occurred prior to the routine use of the nasoseptal flap; in our last five cases we have reconstructed the skull base defect with fat, fascia lata, and the Hadad-Bassagasteguy nasoseptal flap ${ }^{17}$ with no postoperative CSF leaks.

\section{Residual Disease and Recurrence}

Residual disease was found in two primary cases (29\%) and five revision cases (71\%) by early follow-up MRI surveillance ( - Fig. 1). We have not noted any late recurrences ( $>2$ years) in the primary cohort. Within the revision cohort there have been two late recurrences (15\%) occurring at 3.5 years and 5 years.

\section{Overall Status and Mortality}

Overall disease-free progress rates are $71 \%(n=5)$ in primary surgeries and $14 \%(n=1)$ in revision surgeries. Two patients died due to progression of residual disease, with both cases being recurrent tumors with incomplete resection. Within the remaining patients, two (17\%) have progressive residual disease and are awaiting further treatment, three (25\%) have stable residual disease under close surveillance, and seven (54\%) are disease free.

Table 3 Primary versus Revision Surgical Cases

\begin{tabular}{|l|l|l|}
\hline & Primary & Revision \\
\hline $\mathrm{N}$ & 7 & 7 \\
\hline Age (years) & 46.3 & 43.9 \\
\hline Sex M:F & $3: 4$ & $5: 2$ \\
\hline Neurological deficit on presentation & $2(29 \%)$ & $6(86 \%)$ \\
\hline Macroscopic resection & $5(71 \%)$ & $2(29 \%)$ \\
\hline Operative time & $338.8+/-132$ & $443.6+/-161$ \\
\hline Mean length of stay & 12.4 & 15.43 \\
\hline Postoperative complications & $1(14 \%)$ & $3(43 \%)$ \\
\hline Postoperative CSF leak & $2(29 \%)$ & $1(14 \%)$ \\
\hline Radiological residual & $2(29 \%)$ & $5(71 \%)$ \\
\hline Radiotherapy & 1 adjuvant proton beam & 2 adjuvant, 1 RT post surgical recurrence, 1 palliative, \\
& & 3 previous RT \\
\hline Late recurrence & $0(0 \%)$ & $2(29 \%)$ \\
\hline Mortality & $0(0 \%)$ & $2(29 \%)$ \\
\hline Disease-free survival & $5(71 \%)$ & $2(29 \%)$ \\
\hline Follow-up & $41.1(2-104)$ & $35(14-98)$ \\
\hline
\end{tabular}

CSF, cerebrospinal fluid; RT, radiotherapy. 


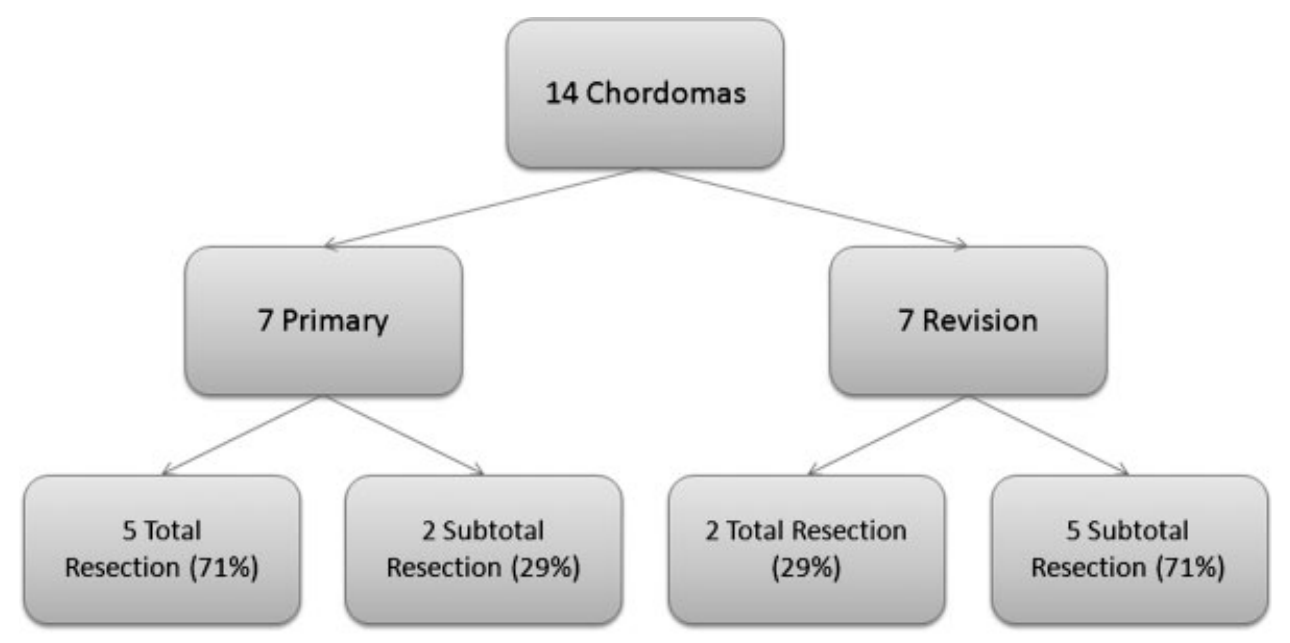

Figure 1 Resection Outcomes in Primary versus Revision Surgery.

\section{Discussion}

This is the second largest study with the longest mean followup to date reporting outcomes of clival chordomas removed with an endoscopic transnasal technique. The outcomes achieved by this unit are comparable with published literature and offer significant advantages over an open approach.

The aim of chordoma surgery is maximal tumor resection and minimal surgical morbidity. Clival lesions are difficult to treat predominantly due to surgical access and the risk to surrounding neurovascular structures, including the carotid artery, brain stem, and lower cranial nerves.

The traditional surgical approach has been an anterior, lateral, or paramedian open approach. ${ }^{18-20}$ Resection rates via open approach range from 61.7 to $79 \%{ }^{21-23} \mathrm{~A}$ significant downside of open surgery is the high risk of permanent neurological deficit, reported at up to $29 \%{ }^{23}$.

The endoscopic transnasal approach has gained considerable interest in the last decade. Chordomas arise in the midline lesions and are therefore ideally suited to a transnasal approach. It avoids significant brain retraction, which is a potential disadvantage of the open approach. This approach also minimizes transgression of neurovascular structures, which is one of the guiding principles of skull base surgery. High-definition endoscopic camera systems and angled telescopes facilitate access by providing the skull base surgeon with exquisite anatomical detail and an ability to see around corners in this critical area.

Other outcomes are comparable with the results achieved at other institutions. The macroscopic resection rate of $7 / 14$ (50\%) and CSF leak rate of $3 / 14(21 \%)$ is on par with reported endoscopic studies of comparable numbers ( - Table 4 ). We do note that since the routine use of the nasoseptal flap, our CSF leak rate has been $0 / 5(0 \%)$.

Patients undergoing primary resection appear to have better outcomes than those who undergo revision surgery. In this series, complete macroscopic surgical resection was achieved in $71 \%$ of primary surgeries and in $29 \%$ of revision cases (-Fig. 1). This finding is noted in other series ${ }^{12,24}$ and is mirrored in the treatment of chordoma at other primary sites. $^{25}$

Repair of the cranial vault has historically been a technically challenging issue for endonasal skull base surgeons, relying on fat, fascia, and catheter balloons to maintain the closure. However, recent advances in surgical techniques including the use of traditional multilayered free tissue flaps, as well as the "gasket-seal" 26 or the Hadad-Bassagasteguy nasoseptal flap, ${ }^{17}$ have led to significantly increased confidence in obtaining a watertight closure of the skull base defect. Indeed, in our five most recent cases using the nasoseptal flap, we did not note any postoperative CSF leaks, which mirrors our experience in dealing with other cranial base tumors. ${ }^{27}$ The success of this vascularized flap depends on the harvesting of sufficient mucosa to allow a tension-free overlay of the flap onto bone surrounding the skull base defect. The septal mucosa has a tendency to shorten after being raised, so we advocate making the flap much larger than the size of the defect. The septal flap can be raised anteriorly as far forward as the mucocutanueous junction, superomedially high up under the nasal dorsum, and inferolaterally extending onto the floor of the nose. Furthermore, we aim to raise the flap contralateral to the tumor when there is significant lateral extension that will require a transpterygoid extension of the dissection.

There was one major intraoperative complication when the basilar artery was injured during sharp dissection of a previously irradiated and consequently very firm tumor. This was managed using the principles and techniques learned from a sheep model of vascular injury pioneered by this department. ${ }^{28}$ The blood pressure was maintained so as not to compromise cerebral perfusion, and the injury was repaired using crushed muscle. ${ }^{29}$ Regular postoperative magnetic resonance angiograms show no pseudoaneurysm formation. All members of the skull base team practice the management of such vascular injuries in the animal laboratory and in regular courses convened by the department.

The two late recurrences both occurred in patients who had undergone revision surgery. The first patient underwent 


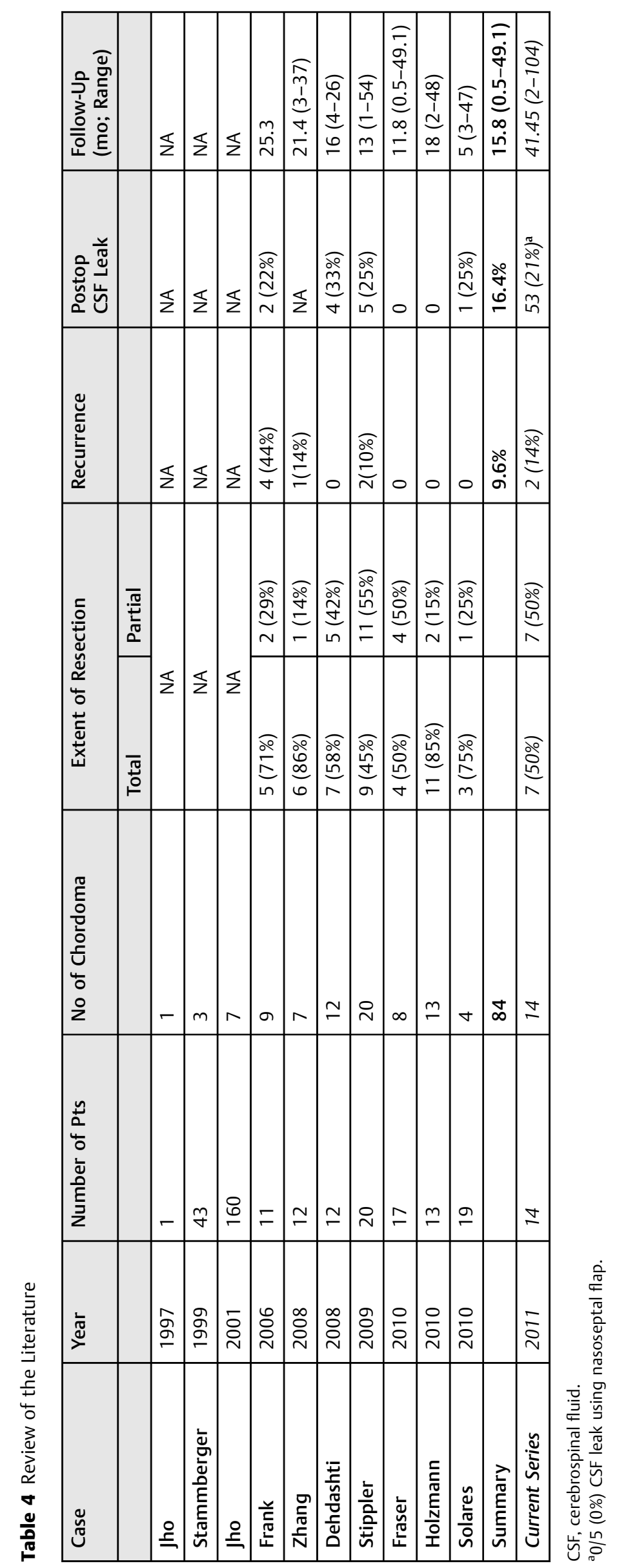


a revision debulking procedure followed by postoperative radiotherapy and appeared clinically free of disease. However, she re-presented 35 months later with rapidly progressive cranial nerve palsies, ultimately dying due to disease progression. The second patient underwent total endoscopic tumor resection, having had a prior external approach resection 5 years earlier. He developed a local recurrence 2 years postsurgery that was treated with intensity modulated radiation therapy and has remained disease free for a further 6 years with no neurological deficit.

\section{Conclusion}

This series illustrates that endoscopic resection of skull base chordoma is a safe and viable alternative to the traditional open approach. Furthermore, it highlights the fact that the primary attempt at surgery offers the best chance to achieve a total resection. Further follow-up will be important to assess the long-term outcomes in this patient group. A team-based approach with each member having appropriate training and experience is critical. With the evolution in equipment, operator skills, and techniques for skull base resection and repair, more skull base lesions are likely to be tackled endoscopically in the future.

\section{Acknowledgments}

PJ Wormald receives royalties from Medtronic for instrument designed and is a consultant for Neilmed Pty Ltd.

\section{References}

1 McMaster ML, Goldstein AM, Bromley CM, Ishibe N, Parry DM. Chordoma: incidence and survival patterns in the United States, 1973-1995. Cancer Causes Control 2001;12:1-11

2 Unni KK. Dahlin's bone tumors: general aspects and data on 11,087 cases. 5th ed. Philadelphia, PA: Lippincott-Raven; 1996

3 Volpe NJ, Liebsch NJ, Munzenrider JE, Lessell S. Neuro-ophthalmologic findings in chordoma and chondrosarcoma of the skull base. Am J Ophthalmol 1993;115:97-104

4 Forsyth PA, Cascino TL, Shaw EG, et al. Intracranial chordomas: a clinicopathological and prognostic study of 51 cases. J Neurosurg 1993;78:741-747

5 Sopta J, Tulic G, Mijucic V, Mamontov P, Mandic N. Solitary lymph node metastasis without local recurrence of primary chordoma. Eur Spine J 2009;18(Suppl 2):191-195

6 Tavernaraki A, Andriotis E, Moutaftsis E, Attard A, Liodantonaki P, Stasinopoulou M. Isolated liver metastasis from sacral chordoma. Case report and review of the literature. J BUON 2003;8:381-383

7 Ogi H, Kiryu H, Hori Y, Fukui M. Cutaneous metastasis of CNS chordoma. Am J Dermatopathol 1995;17:599-602

8 Jho HD, Carrau RL, McLaughlin MR, Somaza SC. Endoscopic transsphenoidal resection of a large chordoma in the posterior fossa. Acta Neurochir (Wien) 1997;139:343-347, discussion 347-348

9 Jho HD, Carrau RL, McLaughlin ML, Somaza SC. Endoscopic transsphenoidal resection of a large chordoma in the posterior fossa. Case report. Neurosurg Focus 1996;1:e3, discussion 1p, e3

10 Fraser JF, Nyquist GG, Moore N, Anand VK, Schwartz TH. Endoscopic endonasal transclival resection of chordomas: operative technique, clinical outcome, and review of the literature. J Neurosurg 2010;112:1061-1069
11 Fraser JF, Nyquist GG, Moore N, Anand VK, Schwartz TH. Endoscopic endonasal minimal access approach to the clivus: case series and technical nuances. Neurosurg 2010;67(3 Suppl Operative):ons150-ons158; discussion ons158

12 Stippler M, Gardner PA, Snyderman CH, et al. Endoscopic endonasal approach for clival chordomas. Neurosurgery 2009;64: 268-277; discussion 277-268

13 Kassam A, Thomas AJ, Snyderman C, et al. Fully endoscopic expanded endonasal approach treating skull base lesions in pediatric patients. J Neurosurg 2007;106(2, Suppl):75-86

14 Kassam AB, Snyderman C, Gardner P, Carrau R, Spiro R. The expanded endonasal approach: a fully endoscopic transnasal approach and resection of the odontoid process: technical case report. Neurosurgery 2005;57(1, Suppl):E213; discussion E213

15 Kassam AB, Gardner P, Snyderman C, Mintz A, Carrau R. Expanded endonasal approach: fully endoscopic, completely transnasal approach to the middle third of the clivus, petrous bone, middle cranial fossa, and infratemporal fossa. Neurosurg Focus 2005; 19:E6

16 Snyderman CH, Pant H, Carrau RL, Prevedello D, Gardner P, Kassam $\mathrm{AB}$. What are the limits of endoscopic sinus surgery?: the expanded endonasal approach to the skull base Keio J Med 2009;58: 152-160

17 Hadad G, Bassagasteguy L, Carrau RL, et al. A novel reconstructive technique after endoscopic expanded endonasal approaches: vascular pedicle nasoseptal flap. Laryngoscope 2006;116:18821886

18 Choo YS, Joo SW, Noh SJ, Lee SI. Intradural retroclival chordoma. J Korean Neurosurg Soc 2009;46:152-155

19 Morisako H, Goto T, Nagata T, et al. Middle skull base approach with postero-lateral mobilization of the geniculate ganglion to access the clival regions. Neurosurgery 2011;69(1 Suppl Operative): ons88-94; discussion ons94.

20 Bozbuğa M, Turan Süslü H, Güler I, Bilgi B, Bayindir C. Removal of clival chordoma in an adolescent thorough combned pterional transsylvian and anterior temporal approach. Turk Neurosurg 2007; 17:55-59

21 Yoneoka Y, Tsumanuma I, Fukuda M, et al. Cranial base chordomalong term outcome and review of the literature. Acta Neurochir (Wien) 2008;150:773-778, discussion 778

22 Tzortzidis F, Elahi F, Wright DC, Temkin N, Natarajan SK, Sekhar LN Patient outcome at long-term follow-up after aggressive microsurgical resection of cranial base chondrosarcomas. Neurosurgery 2006;58:1090-1098, discussion 1090-1098

23 Colli BO, Al-Mefty O. Chordomas of the skull base: follow-up review and prognostic factors. Neurosurg Focus 2001;10:E1

24 Gay E, Sekhar LN, Rubinstein E, et al. Chordomas and chondrosarcomas of the cranial base: results and follow-up of 60 patients. Neurosurgery 1995;36:887-896; discussion 896-887

25 Park L, Delaney TF, Liebsch NJ, et al. Sacral chordomas: Impact of high-dose proton/photon-beam radiation therapy combined with or without surgery for primary versus recurrent tumor. Int J Radiat Oncol Biol Phys 2006;65:1514-1521

26 Leng LZ, Brown S, Anand VK, Schwartz TH. "Gasket-seal" watertight closure in minimal-access endoscopic cranial base surgery. Neurosurgery 2008;62(5 Suppl 2): ONSE342-3; discussion ONSE343

27 Jardeleza C, Seiberling K, Floreani S, Wormald PJ. Surgical outcomes of endoscopic management of adenocarcinoma of the sinonasal cavity. Rhinology 2009;47:354-361

28 Valentine R, Wormald PJ. Controlling the surgical field during a large endoscopic vascular injury. Laryngoscope 2011;121: 562-566

29 Valentine R, Boase S, Jervis-Bardy J, Dones Cabral JD, Robinson S, Wormald PJ. The efficacy of hemostatic techniques in the sheep model of carotid artery injury. Int Forum Allergy Rhinol 2011; $1: 118-122$ 